UDC 542.9:547

\title{
SYNTHESIS OF BETULIN DIFORMATE AND ALLOBETULIN FORMATE DIRECTLY FROM OUTER BIRCH BARK ${ }^{*}$
}

\author{
(C) S. Arrous**, I. Boudebouz, A. Bakibaev \\ Department of Chemistry, Faculty of Science, Tomsk State University, Lenin Avenue \\ 36, Tomsk634050(Russia), e-mail: parroussalinkov@yahoo.com
}

\begin{abstract}
One of the promising directions of birch bark utilization is its extractive treatment with obtaining a number of valuable chemical components among which the most relevant is betulin. As a rule, the methods of betulin esters are multistage and based on classical reactions of betulin acylation; betulin should be preliminarily extracted from birch bark.

The purpose of the present research was synthesis of the betulin diformate and allobetulin formate directly from the birch bark without a separate stage of the betulin preparation. The external layer of the bark of birch, Betula pendula Roth was ground to particle size of $10-20 \mathrm{~mm}$ and used as the raw material. The method is based on combined extraction of betulin from outer birch bark and its formylation with formic acid at reflux for 16 hours. During the treatment of birch bark with formic acid, along with betulin extraction into solution, its formylation into betulin diformate and allobetulin formate occurs. The yield of the formation of betulin diformate and allobetulin formate of the mass of acylated upper bark (a.u.b.) was 40 and 10\%, respectively. The first fraction of betulin diformate was obtained from the resulted solution by evaporating 3/4 of the solution and poured it in water to form beige precipitate, whereas the second fraction was extracted by treating the resulted birch bark by acetone followed by evaporation. However, the allobetulin formate was formed from the second treatment of resulted birch bark by chloroforrm followed by evaporation. Betulin diformate was found to be the main component of this extraction, and it was recrystallized from ethyl alcohol to afford beige powder, and its melting point is $165^{\circ} \mathrm{C}$. The structures of betulin diformate and allobetulin formate are confirmed by ${ }^{1} \mathrm{H}$ NMR, ${ }^{13} \mathrm{C}$ NMR, and FTIR spectroscopy.

Keywords:upper birch bark, betulin diformate, formic acid, allobetulin formate, formylation, betulin.
\end{abstract}

\section{Introduction}

During the multistep synthesis of natural products, the efficiency of the synthetic protocol employed often depends largely on protection and deprotection of the functional groups. To this end, protecting groups have played a crucial role in the synthesis of complex natural products [1]. Acetylation and formylation of hydroxy groups are the most widely used transformations in organic synthesis [2-4].

Formylation is an important reaction in organic chemistry because it can affect selectivity by putting acetate or other ester protecting groups on a substrate [5]. Furthermore, if the alcoholic group is to be oxidized later in the synthetic scheme, the formylated alcoholic does not need to be deprotected, in which case direct oxidation under Oppenauer conditions can be used [6]. In addition, formate esters are useful synthetic reagents and intermediates [7-9].

Natural triterpenoids of the lupane group are of great interest because of their availability and broad spectrum of biological activities [10-12]. Chemical transformations of these compounds at the C-3, C-20, and C-28 positions produced synthetic derivatives that were more effective compared with the starting ones and possessed selective action [13-16]. Recent achievements suggest that preparations based on lupane triterpenoids are promising for application to the therapy of certain diseases $[17,18]$.

Salah Arrous - PhD student,

e-mail: parroussalinkov@yahoo.com

ImeneBoudebouz - PhD student,

e-mail: imene_boudebouz@yahoo.ca

BakibaevAbdigali - Professor, Doctor of Chemical Sciences, e-mail: bakibaev@mail.ru
The birch tree (Betula sp., Betulaceae) is one of the substantial source of pentacyclic triterpenoids. Extracts of the outer bark of different types of birch predominantly contain pentacyclic triterpenoids of the lupan family. One of the promising directions of birch

\footnotetext{
${ }^{*}$ The article has electronic supplementary material (Appendix). DOI: 10.14258/jcprm.2019014682s.

*** Corresponding author.
} 
bark utilization is its extractive treatment with obtaining a number of valuable chemical components among which the most relevant is betulin.

The lupane-type triterpenoids betulin (1) and its many derivatives combine availability and valuable biological activity [19-21]. The protection of C-3 and C-28 using formylation method can serves as the raw material for many organic syntheses, and especially conversions involving the isopropenyl group which are relatively unstudied.

Several formylation procedures have been reported, but these were based on formylation with formic acid in the presence of a dehydrating agent [22-24].

The goal of the present work was to obtain betulin diformate and allobetulin formate directly from birch bark using a simple and efficient method, that could be scaled up to a large scale industrial production.

\section{Results and discussion}

It is well known that the reaction of betulin with strong acids gives allobetulin. The reaction of betulin with boiling formic acid was carried out for the first time by Schulze and Pieroh giving allobetulin formate [25] and was later applied by other authors.[26,27]

In the present study we propose a new single step of the synthesis of a new betulin derivative, which is betulin diformate (2) along with the formation of allobetulin formate (3) directly from the outer birch bark without a separate stage of the betulin (1) preparation. The treatment of the upper birch bark with formic acid results in both the betulin extraction and the betulin formylation.

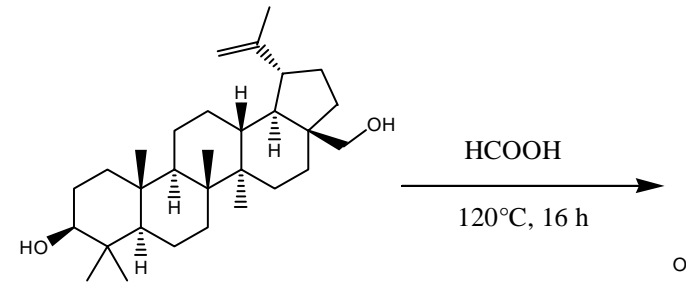

1

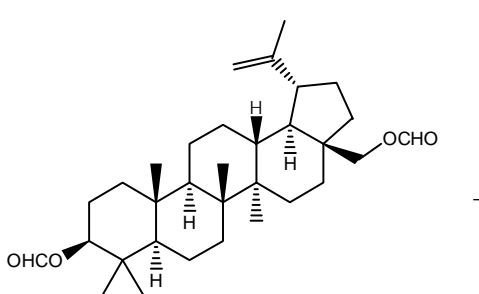

2

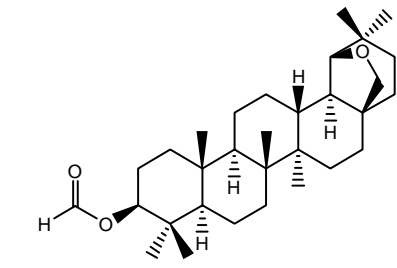

3

Figure 1. Reaction of betulin with formic acid

The boiling of birch bark in formic acid for 16 hours leads to the total conversion of betulin into its corresponding diformate and allobetulin formate (scheme1), the ratio of the outer bark mass to the volume of formic acid was from $1: 6$, and the size of the outer birch fraction was from 10-20 mm. The yield of the formation of betulin diformate was $40 \%$ of the mass of acylated upper bark (a.u.b.), whereas the yield of allobetulin formate was only $10 \%$ of the a.u.b.

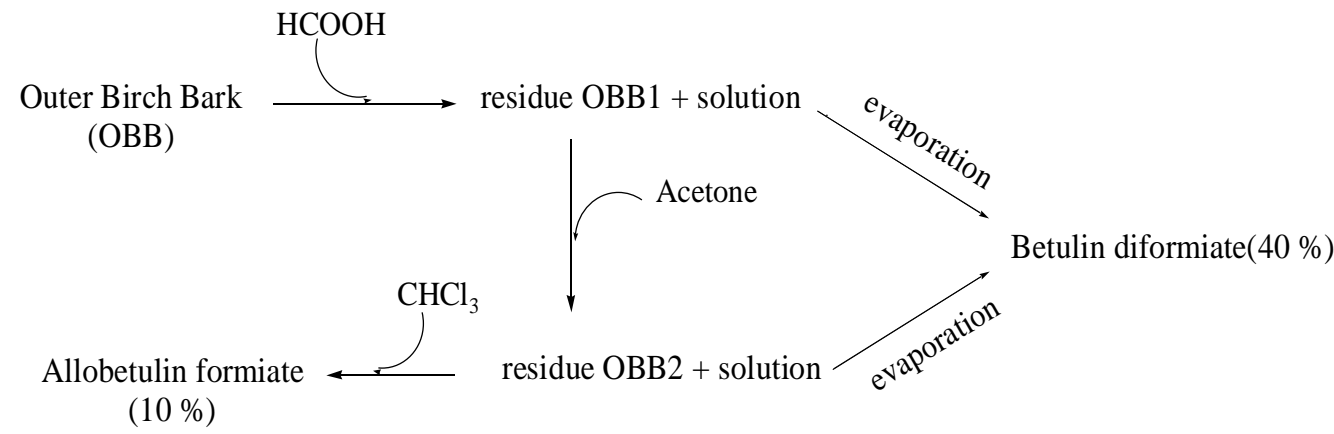

Figure 2. Organogram of the synthesis of betulindiformate and allobetulinformate

Betulin (1) gave the corresponding betulin diformate by: firstly evaporating the resulted solution of formic acid, which gives only betulin diformate (2) (scheme2), and secondly by the treatment of resulted outer birch bark (OBB1) with acetone followed by evaporation of the solvent to afford a white solid, and the analysis of spectroscopic data showed formation of betulin diformate. 
However, after the extraction of betulin diformate from the resulted outer birch bark (OBB1), we noticed that the resulted outer birch bark (OBB2) was mixed with white solid. An attempt to obtain and identify the white solid was done by treating resulted outer birch bark (OBB2) with chloroform at reflux (scheme2), which afforded corresponding ring E rearranged product (3) along with the formation of formyl group in C-3.

The course of the reaction was monitored by thin layer chromatography (TLC). The workup and isolation of the products were easy. The formylated betulin was characterized by comparison of its TLC, IR spectra, ${ }^{1} \mathrm{H}-$ NMR, ${ }^{13} \mathrm{C}-\mathrm{NMR}$ spectra, and melting point with betulin.

The formation of the betulin diformate was evidenced both by the appearance of two proton singlets at $\delta 8.13$ and $\delta 8.15 \mathrm{ppm}$ in its ${ }^{1} \mathrm{H}$ NMR spectrum, and the presence of resonances of two carbonyls groups at $\delta 161.23$ and $\delta$ $161.62 \mathrm{ppm}$ in its ${ }^{13} \mathrm{C}$ NMR. As was evident by infrared spectrum, which indicated the absence $\mathrm{O}-\mathrm{H}$ stretching band and the presence of $\mathrm{C}-\mathrm{H}$ (alkane), $-\mathrm{CH}_{3}$ (bending), $\mathrm{C}=\mathrm{C}, \mathrm{C}-\mathrm{O}$ and $\mathrm{C}=\mathrm{O}$ group.

The ${ }^{1} \mathrm{H}$ NMR spectrum of the betulin diformate showed two singlets centered at $\delta 4.61$ and $4.71 \mathrm{ppm}$ and were attributable to the terminal methylene of the olefinic group, as well as a set of singlets representing six methyl groups at $\delta 0.87,0.89,0.99,1.05$ and $1.70 \mathrm{ppm}$. The multiplet at $\delta 4.58 \mathrm{ppm}$, which was suggested that attributable to a methine proton in the axial orientation bonded at $\mathrm{C}-3$. two doublet, attributable to two methylene protons centered at $\delta 3.95$ and $4.37 \mathrm{ppm}$, consecutively.

The ${ }^{13} \mathrm{C}$ NMR spectrum of the betulin diformate showed signals at $\delta 110.03$ and $\delta 149.97$ ppm corresponding to a terminal methylene carbon and a quaternary carbon atom of the olefinic proup, and the presence of resonances for the two carbonyl groups at $\delta 161.23$ and $\delta 161.62$.

Betulin diformate was also identified by infrared spectrum, which indicated the absence O-H stretching band and the presence of the stretching vibrations of the $\mathrm{C}-\mathrm{H}$ bonds in the $\mathrm{CH}_{2}$ groups at $v(\mathrm{C}-\mathrm{H})$ as $=2924.19 \mathrm{~cm}^{-1}, v(\mathrm{C}-$ $\mathrm{H}) \mathrm{s}=2855.41 \mathrm{~cm}^{-1}$, the deformation vibrations of the $\mathrm{C}-\mathrm{H}$ bonds in the $\mathrm{CH}_{2}$ groups occurs at $\delta(\mathrm{C}-\mathrm{H})$ as $=1448.34$ $\mathrm{cm}^{-1}$ (planar scissoring vibration), and the stretching vibration of $(\mathrm{C}=\mathrm{C})$ group was appeared at $1649.86 \mathrm{~cm}^{-1}$, The stretching vibration of the $\mathrm{C}-\mathrm{O}$ bond is observed in the region of $1247.35-1000 \mathrm{~cm}^{-1}$ at $v(\mathrm{C}-\mathrm{O})=1031.59$ and $1247.35 \mathrm{~cm}^{-1}$, and the stretching vibration of the carbonyl group at $v(\mathrm{C}=\mathrm{O}) 1726.56 \mathrm{~cm}^{-1}$.

The formation of allobetulin formate was confirmed by IR spectrum, which displayed the absence of the vibration band of hydroxyl group at $3372 \mathrm{~cm}^{-1}$, and the appearance of a new strong pick at $1726.04 \mathrm{~cm}^{-1}$ designable to the carbonyl group $(\mathrm{C}=\mathrm{O})$, which indicates the formation of formyl group on position $\mathrm{C}-3$, as it was evident by the disappearance of the band at $1640 \mathrm{~cm}^{-1}$ and $800 \mathrm{~cm}^{-1}$ indicating the absence of vinylidene $\mathrm{C}=\mathrm{C}$ vibrations and the formation of The tetrahydrofuran ring.

The ${ }^{1} \mathrm{H}$ NMR spectrum of allobetulinformate showed that the signals at 4.59 and $4.69 \mathrm{ppm}$ of the olefinic region are missing, along with The formation of tetrahydrofuran ring which appears as doublets of protons of $\mathrm{CH}_{2}$ group ( $A B$ system) at $\delta 3.37$ and $3.70 \mathrm{ppm}$, and a singlet of $\mathrm{CH}$ group at $3.47 \mathrm{ppm}$. The multiplets of methine and methylene protons of the lupane scaffold are located at 1.16-1.62 ppm, and the multiplet of proton at C-3 position is shifted to the region $4.54 \mathrm{ppm}$ due to the influence of the formyl fragment. The singlet of the formyl proton at $8.04 \mathrm{ppm}$.

It was also supported by ${ }^{13} \mathrm{C}$ NMR spectroscopy, which confirmed the absence of two olefinic carbons at 110 and $150 \mathrm{ppm}$ and the presence of carbonyl group at $161.24 \mathrm{ppm}$.

\section{Experimental part}

\section{General}

The dry outer birch bark of the Betulapendula Roth birch was used as a starting material. The upper bark was chopped into fractions of 10-20 mm. Analysis of the chemical composition of the external layer of birch bark was carried out using the conventional procedures of wood chemistryand original approaches described in literature[28-30]. The percentages of betulin and water in outer birch bark were found 43.25 and $0.4 \%$ respectively.

Melting points (mp) were determined in open capillaries using Buchi apparatus.

Nuclear magnetic resonance $\left({ }^{1} \mathrm{H}\right.$ NMR, ${ }^{13} \mathrm{C}$ NMR) spectra were recorded on a Bruker Avance III D spectrometer at room temperature operating at $400.17 \mathrm{MHz}$ for ${ }^{1} \mathrm{H}$ atoms and $100.63 \mathrm{MHz}$ for ${ }^{13} \mathrm{C}$ atoms. Chemical shifts (d) are reported relative to tetramethylsilane peak set at $0.00 \mathrm{ppm}$. In the case of multiplets the signals are reported as intervals. Signals were abbreviated as s, singlet; d, doublet; t, triplet;m, multiplet. Coupling constants were expressed in $\mathrm{Hz}$.

The reaction was monitored by TLC on Sorbfil plates using $\mathrm{C}_{6} \mathrm{H}_{6}: \mathrm{CH}_{2} \mathrm{Cl}_{2}: \mathrm{CH}_{3} \mathrm{OH}(5: 5: 1)$. Spots were detected using a reagent ( $1 \%$ phosphomolybdic acid-water) followed by heating at $110^{\circ} \mathrm{C}$ for $5 \mathrm{~min}$. 
Fourier-transform infrared (FTIR) spectra were obtained directly from the products using the high-attenuated total reflectance technique in a Bruker Tensor 27 FT-IR Spectrometer.

The spectra were recorded in the range of 400 to $4000 \mathrm{~cm}^{-1}$ with a resolution of $4 \mathrm{~cm}^{-1}$ over 16 scans.

Synthesis of Compounds 2 and 3

The synthesis of betulin diformate was carried out by treating $50 \mathrm{~g}$ of outer birch bark (OBB) with $300 \mathrm{ml}$ of formic acid at its boiling point in a round bottomed flask equipped with a backflow condenser. After the reaction completion (16 hours), the mixture was filtered, then the solution was concentrated with a rotary evaporator, and the filtrate was diluted with a fivefold amount of water. The precipitated substance was separated by filtering, washed multiply on the filter with distilled water and dried in the air. The product was recrystallized from acetone to give 13 $\mathrm{g}$ of betulindiformate.

The residues of outer birch barck (OBB1) was further extracted with acetone separately for 1 hour at $40{ }^{\circ} \mathrm{C}$, and the extract was concentrated at vacuum rotary evaporator to get $7 \mathrm{~g}$ of betulin diformate. Whereas, the second resulted outer birch bark (OBB2) was further extracted with chloroform for 1hour under reflux, after removing the upper birch bark by filtration the extract was evaporated to give $5 \mathrm{~g}$ allobetulinformate. The product was recrystallized from acetone.

Betulindiformate $20 \mathrm{~g}$ was obtained as beige powder after isolation and recrystallization from acetone $\left(\mathrm{mp} 165^{\circ} \mathrm{C}\right)$.

Betulin 3, 28-di-O-formate (2): Yield $=40 \%$. $\mathrm{Rf}=0.61\left(\mathrm{C}_{6} \mathrm{H}_{6}: \mathrm{CH}_{2} \mathrm{Cl}_{2}: \mathrm{CH}_{3} \mathrm{OH} / 5: 5: 1\right) . \mathrm{mp}=165^{\circ} \mathrm{C} . \mathrm{IR} \mathrm{IR}$ $\left(\mathrm{KBr}, v, \mathrm{~cm}^{-1}\right): 3070.90(=\mathrm{C}-\mathrm{H}), 2924.19-2855.41\left(-\mathrm{CH}_{3}\right.$ and $\left.-\mathrm{CH}_{2}\right), 1726.56(\mathrm{C}=\mathrm{O}), 1649.86(\mathrm{C}=\mathrm{C}), 1247.35$, 1031.59(C-O-C). ${ }^{1} \mathrm{H}$ NMR (400.17 MHz, $\mathrm{CDCl}_{3}, \delta$, ppm, J/Hz): 0.78 (m, 1H, 5-H), 0.87 (s, 3H, $\left.\mathrm{CH}_{3}\right), 0.89(\mathrm{~s}, 6 \mathrm{H}$, $\left.\mathrm{CH}_{3}\right), 0.99\left(\mathrm{~s}, 3 \mathrm{H}, \mathrm{CH}_{3}\right), 1.05\left(\mathrm{~s}, 3 \mathrm{H}, \mathrm{CH}_{3}\right), 1.26-1.95\left(\mathrm{~m}, 10 \mathrm{H}, \mathrm{CH}_{2}\right) ; 1.26(\mathrm{~m}, 1 \mathrm{H}, \mathrm{CH}), 1.42(\mathrm{~m}, 1 \mathrm{H}, \mathrm{CH}), 1.80(\mathrm{~m}$, $1 \mathrm{H}, \mathrm{CH}) ; 1.70$ (s, 3H, C30H3), 8.13 and 8.15 (s, 2H, HCO), 2.46 (t.d, 1H, 19-H, J=11.0, $5.8 \mathrm{~Hz}$ ), 3.95 and 4.37 (d, $1 \mathrm{H}, 28-\mathrm{H}, 2 \mathrm{~J}=11.2 \mathrm{~Hz}), 4.58(\mathrm{~m}, 1 \mathrm{H}, 3-\mathrm{H}), 4.61(\mathrm{~s}, 2 \mathrm{H}, 29-\mathrm{H}), 4.71(\mathrm{~s}, 2 \mathrm{H}, 29-\mathrm{H}) .{ }^{13} \mathrm{C}$ NMR spectrum $(100.63$ $\left.\mathrm{MHz}, \mathrm{CDCl}_{3}, \delta, \mathrm{ppm}\right): 14.75,16.0,16.15,16.51\left(\mathrm{CH}_{3}\right) ; 18.17$ (C6), 19.12(C30), 20.79 (CH2), 23.82 (C2), 25.12 and $26.95\left(\mathrm{CH}_{2}\right), 27.87\left(\mathrm{CH}_{3}\right), 29.47(\mathrm{C} 21) ; 29.61,34.07,34.46\left(\mathrm{CH}_{2}\right) ; 37.05,37.63(\mathrm{C} 13), 37.75,38.35$ $\left(\mathrm{CH}_{2}\right) ; 40.88,42.7,46.3,47.7$ (C19), 48.75 (C18), 50.25 (C9), 55.35 (C5), 62.32 (C28), 81.06 (C3), 110.03 (C29), $149.97(\mathrm{C} 20), 161.23$ and $161.62(\mathrm{C}=\mathrm{O})$.

Allobetulin 3-O-formate (3): White solid. Yield= 10\%. $\mathrm{Rf}=0.63\left(\mathrm{C}_{6} \mathrm{H}_{6}: \mathrm{CH}_{2} \mathrm{Cl}_{2}: \mathrm{CH}_{3} \mathrm{OH} / 5: 5: 1\right) . \mathrm{mp}=314$ ${ }^{\circ} \mathrm{C}$ (lit., [25] $\left.315^{\circ} \mathrm{C}\right)$. IR ( $\left.\mathrm{KBr}, v, \mathrm{~cm}^{-1}\right)$ : 2924.37-2856.03 (- $\mathrm{CH}_{3}$ and $\left.-\mathrm{CH}_{2}\right), 1726.04(\mathrm{C}=\mathrm{O}), 1247.47-1023.27(\mathrm{C}-\mathrm{O}-$ C). ${ }^{1} \mathrm{H}$ NMR (400.17 MHz, $\left.\mathrm{CDCl}_{3}, \delta, \mathrm{ppm}\right): 0.73\left(\mathrm{~s}, 3 \mathrm{H}, \mathrm{CH}_{3}\right), 0.79\left(\mathrm{~s}, 3 \mathrm{H}, \mathrm{CH}_{3}\right), 0.80\left(\mathrm{~s}, 3 \mathrm{H}, \mathrm{CH}_{3}\right), 0.84(\mathrm{~s}, 3 \mathrm{H}$, $\left.\mathrm{CH}_{3}\right), 0.86\left(\mathrm{~s}, 3 \mathrm{H}, \mathrm{CH}_{3}\right), 0.89$ (s, 3H, $\left.\mathrm{CH}_{3}\right), 0.97\left(\mathrm{~s}, 3 \mathrm{H}, \mathrm{CH}_{3}\right), 3.36$ (d, 1H, J 7.6, 28-Ha), 3.47 (s, 1H, 19a-H), 3.70 $\left(\mathrm{d}, 1 \mathrm{H}, J\right.$ 7.6, 28-Hb), $4.54(\mathrm{~m}, 1 \mathrm{H}, 3 \mathrm{a}-\mathrm{H}), 8.00$ (s, 1H, 3b-COH). ${ }^{13} \mathrm{C} \mathrm{NMR}\left(100.63 \mathrm{MHz}, \mathrm{CDCl}_{3}, \delta, \mathrm{ppm}\right): 13.52$ (C27), 15.39 (C24), 15.72 (C26), 16.50 (C25), 18.26 (C6), 21.00 (C11), 23.81, 24.56 (C29 or C30), 26.25 (CH2), 26.42 (CH2), 27.86 (C23), 28.82 (C29 or C30), 32.69 (C21), 33.81 (C7), 34.12 (C13), 36.28 (C17), 36.72 (C16), 37.15 (C10), 37.76 (C4), 38.56 (C1), 40.62 (C), 40.72 (C), 41.48 (C), 46.80 (C18), 50.98 (C9), 55.48 (C5), 71.26 (C28), 81.07 (C3), 87.96 (C19), $161.24(\mathrm{C}=\mathrm{O})$.

\section{Conclusion}

In this study, the synthesis of betulin diformate has been achieved for the first time. along with the extraction of allobetulinformate directly from outer birch bark. The structure of betulin diformate and allobetulin formate were confirmed by FTIR, ${ }^{1} \mathrm{H}-\mathrm{NMR}$, and ${ }^{13} \mathrm{C}$ NMR spectroscopy.

betulin diformate is the main component of this extraction. The product yield was $40 \%$ of the a.u.b.

\section{Acknowledgement}

This work was supported by the Ministry of Education and Science of the Russian Federation (grant nos. 0513108).

\section{References}

1. Hagiwara H., Morohashi K., Sakai H., Suzuki T., Ando M. Tetrahedron,1998,vol. 54,pp. 5845. DOI: 10.1016/S00404020(98)00255-5.

2. Shirini F., Zolfigol M. A., Mallakpour S. Russ. J. Org. Chem., 2005,vol. 41,pp. 625. DOI:10.1007/s11178-005-0217-8.

3. Shirini F., Zolfigol M. A., Abedini M., Salehi P. Bull.Korean. Chem. Soc., 2003, vol. 24,pp. 1683. DOI: 10.5012/bkcs.2003.24.11.1683. 
4. Lee C. W., Hwang H. Y., Jeong H. M., Yoon U. C., Chi K. W. Synth Met., 2009,vol. 159, pp. 1820. DOI: 10.1016/j.synthmet.2009.05.033.

5. Greene T.W., Wuts P.G.M. Protective Groups in Organic Synthesis. New York ; Wiley, 1999.

6. Rignold H.J., Loeken B., Roseknranz G., Sondheimer F.J. Am. Chem. Soc., 1956, vol. 78, pp. 816.DOI: 10.1021/ja01585a030.

7. Mandai T., Matsumoto T., Kawada M., Tsuji J. J. Org. Chem., 1992, vol. 57, pp. 1326.DOI:10.1021/jo00031a005.

8. Garner C.M., Prince M.E.Tetrahedron. Lett., 1994, vol. 35, pp. 2463. DOI: 10.1016/S0040-40399(00)77144-9.

9. Ali B.E., Alper H. J. Mol. Catal. A., 1995, vol. 96, pp. 197. DOI: 10.1016/1381-1169(94)00048-4.

10. Melzig M.F., Bormann H. Planta. Med., 1998, vol. 64, pp. 655.DOI:10.1055/s-2006-957542.

11. Schmidt M.L., Kuzmanoff K.L., Ling-Indeck L.,Pezzuto J.M. Eur. J. Cancer., 1997, vol. 33, pp. 2007. DOI: 10.1016/S0959-8049(97)00294-3.

12. Kim D.S.H.L., Pezzuto J.M., Pisha E. Bioorg. Med. Chem. Lett.,1998, vol. 8, pp. 1707. DOI: 10.1016/S0960894X(98)00295-9.

13. Lee K.H.Curr. Topics Med. Chem. (Hilversum, Neth.), 2003, vol.3, pp. 155.DOI: 10.2174/1568026033392435.

14. Hiroya K., Takahashi T., Miura N., Naganuma A., Sakamoto T. J. Bioorg. Med. Chem., 2002, vol. 10, pp. 3229.DOI:10.1016/S0968-0896(02)00172-4.

15. Kim J.Y., Koo H.M., Kim D.S.H.L.Bioorg.Med. Chem. Lett.,2001, vol. 11, pp. 2405.DOI:10.1016/S0960894X(01)00460-7.

16. Flekhter O.B., Boreko E.I., Nigmatullina L.R., Pavlova N.I., Nikolaeva S.N., Savinova O.V., Eremin V.F., Baltina L.A., Galin F.Z., Tolstikov G.A. Bioorg. Khim.,2003, vol.29, pp. 326.DOI: 10.1023/A:1023948919315.

17. Lee K.H.J. Nat. Prod., 2004, vol.67, pp. 273.DOI: 10.1021/np030373o.

18. Cos P., Berghe D.V., Hermans N., Pieters L., Vlietinck A. J. Nat. Prod.,2004, vol. 67, pp. 284.DOI: $10.1021 / \mathrm{np} 034016 \mathrm{p}$.

19. Tolstikov G.A., Flekhter O.B., Shults E.E., Baltina L.A., Tolstikov A.G. Khim. InteresakhUstoich. Razvit., 2005 , vol. 13, pp. 1. (in Russ.).

20. Patocka J.J. Appl. Biomed.,2003, vol. 1, pp. 7.

21. Sami A., Taru M., Salme K., Jari Y.K. Eur. J. Pharm. Sci., 2006, vol. 29, pp. 1. DOI:10.1016/j.ejps.2006.04.006.

22. Strazzolini P., Giumanian A.G., Causi S. Tetrahedron, 1990, vol. 46, pp. 1081. DOI: 10.1016/S0040-4020(01)86676-X.

23. Olah G.A., Vankar Y.D., Arvanaghi M., Sommer M.J.Angew. Chem, Int Ed., 1979, vol. 18, pp. 614.DOI: 10.1002/anie.197906141.

24. Kitagawa T., Arita J., Nagahata A.Chem Pharm Bull., 1994, vol. 42, pp. 1655. DOI: 10.1248/cpb.42.1655.

25. Schulze H.,Pieroh K. Chem. Ber., 1922, vol. 55, pp. 2332-2346. DOI: 10.1002/cber.19220550814.

26. Lugemwa F.N., Huang F.Y., Bentley M.D., Mendel M.J., Alford A.R.A. J. Agric. Food Chem., 1990,vol. 38, pp. 493496. DOI: $10.1021 / \mathrm{jf00092a035.}$

27. Errington S.G., Ghisalberti E.L., Jefferies P.R.Aust. J. Chem., 1976, vol. 29, pp. 1809-1814.DOI: 10.1071/CH9761809.

28. Obolenskaya A.V., Elnitskaya Z.P., Leonovich A.A. Laboratornyyerabotypokhimiidrevesinyitsellyulozy.[Laboratory works on chemistry of wood and cellulose]. Moscow, 1991, 320 p. (in Russ.).

29. Patent 2074867 (RU).1997.(in Russ.).

30. Patent 2119503 (RU).1998.(in Russ.).

ReceivedDecember7, 2018

Revised December 27, 2018

Accepted December27, 2018

For citing: Arrous S., Boudebouz I., Bakibaev A. Khimiya Rastitel'nogo Syr'ya, 2019, no. 1, pp. 113-117. (in Russ.).DOI: $10.14258 /$ jcprm.2019014682. 
